\title{
New developments in the management of Waldenström macroglobulinemia
}

\section{Jithma P Abeykoon' \\ Uday Yanamandra ${ }^{2}$ \\ Prashant Kapoor ${ }^{1,3}$}

'Department of Internal Medicine, Mayo Clinic, Rochester, MN, USA;

${ }^{2}$ Department of Hematology and Stem Cell Transplant, Army Hospital

(Research \& Referral), Delhi, India;

${ }^{3}$ Division of Hematology, Mayo Clinic, Rochester, MN, USA
Correspondence: Prashant Kapoor Division of Hematology, Mayo Clinic, 200 First Street SW, Rochester, MN 55905, USA

Tel + I 507538 059|

Fax +l 5072664972

Email kapoor.prashant@mayo.edu
This article was published in the following Dove Press journal:

Cancer Management and Research

10 March 2017

Number of times this article has been viewed

Abstract: Waldenström macroglobulinemia (WM) is a rare, immunoglobulin $\mathrm{M}$-associated lymphoplasmacytic lymphoma. With the recent discoveries of $C X C R$ warts, hypogammaglobulinemia, infections, and myelokathexis (WHIM) and MYD88 mutations, our understanding of the biology of WM has expanded substantially. While WM still remains incurable, the field is rapidly evolving, and a number of promising agents with significant activity in this malignancy are being evaluated currently. In this review, we discuss the new developments that have occurred in WM over the past 15 years, with a focus on the role of ibrutinib, an oral Bruton's tyrosine kinase inhibitor that has recently been approved for WM in the United States, Europe, and Canada.

Keywords: lymphoplasmacytic lymphoma, indolent lymphoma, MYD88, CXCR4, management, ibrutinib

\section{Introduction}

The report of two patients by Waldenström ${ }^{1}$ in the year 1944, presenting with epistaxis, hematemesis, lymphadenopathy, decreased fibrinogen level, increased blood viscosity, and elevated macroglobulins, was the first account of Waldenström macroglobulinemia (WM). WM is a rare, indolent lymphoma with lymphoplasmacytic infiltration of the bone marrow (BM) and monoclonal immunoglobulin $\mathrm{M}(\mathrm{IgM})$ gammopathy. The management of WM is evolving, with a deeper understanding of the disease pathophysiology and introduction of newer drugs. WM remains an incurable disease, with a median overall survival (OS) of $\sim 8$ years from diagnosis. ${ }^{2,3}$ In this review, we discuss new developments in the management of WM based on the data published over the past 15 years, with an emphasis on the role of Bruton's tyrosine kinase (BTK) inhibitor, ibrutinib, that has been recently approved for WM in the US, Canada, and European Union. To better serve our patients, a holistic understanding of this fascinating malignancy and its current and emerging therapeutic options remains paramount, and this review has been written with the intention of making our patients the ultimate beneficiaries.

\section{Epidemiology}

Approximately 1,500 new cases of WM are diagnosed in the US each year. ${ }^{4}$ The median age at diagnosis is $\sim 70$ years, with an incidence rate of 3.4 per million among men and 1.7 per million among women in the US. ${ }^{2}$ Caucasians are predominantly affected. ${ }^{5}$

Although no proven inheritance patterns have been observed in WM to date, a population-based study was remarkable for demonstrating a 20-fold increased risk of development of lymphoplasmacytic lymphoma (LPL)/WM in the first-degree relatives 
of the patients. ${ }^{6}$ Moreover, the first-degree relatives were noted to have a three- to fivefold increased risk of developing another non-Hodgkin's lymphoma, chronic lymphocytic leukemia, or monoclonal gammopathy of undetermined significance. ${ }^{6}$

\section{Diagnosis}

The Mayo Clinic criteria that must be met for the diagnosis of active $\mathrm{WM}$ are

1. serum IgM monoclonal protein of any size

2. BM lymphoplasmacytic infiltration of at least $10 \%$.

Besides the BM, the lymphoplasmacytic cells can infiltrate extramedullary sites, predominantly the lymph nodes and the spleen, with a spectrum of clonal B cells, including small lymphocytes, plasmacytoid lymphocytes (showing features of both plasma cells and lymphocytes), and plasma cells. In contrast to the Mayo Clinic criteria, the International Workshop on Waldenström's Macroglobulinemia (IWWM) Consensus criteria merely require the presence of a lymphoplasmacytic infiltrate in the marrow and serum IgM monoclonal protein of any size to establish a diagnosis of WM. The typical immunophenotypic signature of the infiltrate is surface $\mathrm{IgM}^{+}, \mathrm{CD}^{ \pm}, \mathrm{CD} 10^{-}, \mathrm{CD} 19^{+}, \mathrm{CD} 20^{+}, \mathrm{CD} 22^{+}, \mathrm{CD} 23^{-}$, $\mathrm{CD} 25^{+}, \mathrm{CD} 27^{+}, \mathrm{FMC}^{+}, \mathrm{CD} 103^{-}$, and $\mathrm{CD} 138^{+} .7,8$

\section{Pathogenesis}

Although the exact etiology of WM remains unclear to date, the whole genome sequencing (WGS) has identified important mutations that appear to be pathogenic. Recent studies have partially unraveled the role of myeloid differentiation factor 88 (MYD88) mutations in the pathogenesis of WM. The MYD88 protein is involved in the signal transduction pathways activating nuclear factor kappa $B(\mathrm{NF \kappa} \beta)$ and mitogen-activated protein kinase (MAPK). ${ }^{9}$ Its activation is enhanced by the mutations occurring in the MYD88 gene, which induce tumorigenesis. ${ }^{9}$ The WGS in WM has identified a somatic variant $(\mathrm{T} \rightarrow \mathrm{C})$ at position 38182641 in chromosome $3 \mathrm{p} 22.2$ that harbors the $M Y D 88$ gene. ${ }^{10}$ The $M Y D 88^{\mathrm{L} 265 \mathrm{P}}$ mutation leads to an amino-acid change from leucine to proline (L265P) in the MYD88 protein. ${ }^{10}$ The protein is capable of hyperactivating $\mathrm{NF} \kappa \beta$ via interleukin-1 receptor-associated kinase (IRAK) and BTK pathways through phosphorylation, thereby increasing cell survival. ${ }^{11}$ Treon et a ${ }^{10}$ reported that $M Y D 88^{\mathrm{L} 265 \mathrm{P}}$ is a common mutation in WM with a prevalence of $91 \%$. Patients with MYD $88^{\mathrm{L} 265 \mathrm{P}}$ mutation are noted to have distinct disease profile, including higher serum IgM levels, hyperviscosity, and higher BM involvement compared to their counterparts harboring the MYD88 wild-type gene. ${ }^{12}$
Another seminal discovery is that of the somatic mutations involving the C-X-C chemokine receptor type 4 (CXCR4, also known as Fusin or CD184), encoded by the CXCR4 gene. ${ }^{13,14}$ The association in WM bears a striking similarity to the finding observed in the warts, hypogammaglobulinemia, infections, and myelokathexis (WHIM) syndrome that also results from a mutation in the CXCR4 gene. ${ }^{12,15}$ The $C X C R 4$ mutations have been observed in $27-40 \%$ of patients with WM and were found to be involved with its pathogenesis. ${ }^{12,15,16}$ These mutations lead to the formation of a truncated receptor protein associated with a high expression of $C X C R 4$ receptor and could be either nonsense $\left(C X C R 4^{\text {WHIMNS }}\right)$ type or frameshift $\left(C X C R 4^{\text {WHIM/FS }}\right)$ type.

\section{Genotypic-phenotypic association}

A single retrospective study by the Dana-Farber Cancer Institute $^{12}$ noted that the MYD $88^{\mathrm{L} 265 \mathrm{P}}$ with $C X C R 4^{\text {WHIM/NS }}$ genotype was associated with severe disease, greater $\mathrm{BM}$ involvement, and increased likelihood of developing hyperviscosity-related complications with higher serum IgM levels.

The patients with $M Y D 88^{\mathrm{L} 265 \mathrm{P}}$ and $C X C R 4^{\mathrm{WHIM} / \mathrm{FS}}$ genotypes also exhibit an aggressive disease course. However, the disease severity of patients with $M Y D 88^{\mathrm{L} 265 \mathrm{P}}$ and $C X C R 4^{\mathrm{WHIM} / F S}$ genotypes appears milder compared to their MYD $88^{\mathrm{L} 265 \mathrm{P}}$ and $C X C R 4^{\text {WHIM/NS }}$ counterparts (Table 1). ${ }^{12,15}$ The patients with $M Y D 88^{\mathrm{WT}} C X C R 4^{\mathrm{WT}}$ show the lowest marrow involvement. ${ }^{12}$ Despite the association of severe disease with $M Y D 88^{\mathrm{L} 265 \mathrm{P}}$ and $C X C R 4^{\mathrm{WHIM} / \mathrm{NS} \text { or FS }}$ mutations compared to $M Y D 88^{\mathrm{WT}} C X$ $C R 4^{\mathrm{WT}}$, the survival outcomes do not appear to be affected by the presence of $C X C R 4$ mutations. Rather, the outcomes appear to be impacted by the MYD 88 mutation status and were found to be surprisingly better for the patients harboring MYD $88^{\mathrm{L} 265 \mathrm{P}}$ gene than the patients harboring MYD $88^{\mathrm{WT}}$ gene in one study. ${ }^{12}$ Importantly, we now know that the presence of MYD88 and CXCR4 mutations will affect the degree of response to ibrutinib (discussed in the subsequent section). Another recent article on the transcriptional profiling (RNAseq) and comparison of the WM patients to the normal population without B-cell disorders attempted to shed more light on this matter. Four genotypic groups as indicated in Table 1 are currently identifiable. ${ }^{16,17}$

\section{Clinical presentation}

The clinical presentation and the disease characteristics of WM could be attributed to tumor/B-lymphocyte infiltration or monoclonal immunoglobulins as summarized in Table 2.

Presentation of WM could be heterogenous. Some of the most common presenting features are hyperviscosity, 
Table I Genotypic-phenotypic association in WM

\begin{tabular}{|c|c|c|c|c|}
\hline Clinical Characteristics & MYD88 $^{\mathrm{L} 265 \mathrm{P}} \mathrm{CXCR4^{ \textrm {WT } }}$ & MYD88 ${ }^{\mathrm{L} 265 \mathrm{P}} \mathrm{CXCR4^{ \textrm {WHIM } / \mathrm { FS } }}$ & MYD88 ${ }^{\text {L265P }}$ CXCR4 WHIM/NS & MYD88 $^{\mathrm{WT}}$ CXCR4 ${ }^{\mathrm{WT}}$ \\
\hline $\lg M$ & $\uparrow \uparrow$ & $\uparrow \uparrow$ & $\uparrow \uparrow \uparrow \uparrow$ & $\uparrow$ \\
\hline BM infiltration & $\uparrow \uparrow \uparrow$ & $\uparrow \uparrow$ & $\uparrow \uparrow \uparrow \uparrow$ & $\uparrow$ \\
\hline Sensitivity to BTK inhibitors & $\uparrow \uparrow \uparrow$ & $\uparrow \uparrow$ & $\uparrow$ & $\downarrow$ \\
\hline Incidence (\%) & $\sim 60$ & $27-40 *$ & $27-40 *$ & $<10$ \\
\hline
\end{tabular}

Notes: This table is a relative semiquantitative representation of the frequency of disease characteristics with various genetic mutations. *Frameshift (FS) and nonsense (NS) mutations are almost equally divided among WM patients with CXCR4 somatic mutations.

Abbreviations: BM, bone marrow; BTK, Bruton's tyrosine kinase; IgM, immunoglobulin M; WM, Waldenström macroglobulinemia.

Table 2 Disease characteristics of WM

\begin{tabular}{|c|c|}
\hline Parameter & Clinical characteristics \\
\hline \multirow[t]{4}{*}{ Features attributable to tumor infiltration } & Constitutional symptoms: recurrent fever, night sweats, weight loss, and fatigue \\
\hline & Cytopenias due to BM infiltration \\
\hline & Organomegaly \\
\hline & Lymphadenopathy \\
\hline \multirow{5}{*}{$\begin{array}{l}\text { Features attributable to monoclonal } \\
\text { immunoglobulin }\end{array}$} & Hyperviscosity that may present as oro-nasal bleeding, blurred vision, headache, dizziness, vertigo, \\
\hline & Deposition of IgM as amorphous material in heart, kidney, and gastrointestinal tract causing \\
\hline & amyloidosis or lgM infiltrative disease \\
\hline & Coombs' positive autoimmune cold hemolytic anemia and cryoglobulinemia ${ }^{88,89}$ \\
\hline & Neuropathy due to IgM directed against myelin-associated glycoprotein or other neural components ${ }^{90}$ \\
\hline
\end{tabular}

Abbreviations: BM, bone marrow; IgM, immunoglobulin M; WM, Waldenström macroglobulinemia.

constitutional symptoms, bleeding, and neurologic symptoms. ${ }^{18,19}$ Lymphadenopathy, hepatomegaly, splenomegaly, and funduscopic abnormalities may be detected..$^{18,19}$ Anemia is a common presenting feature, and type I cryoglobulinemia may be infrequently encountered. ${ }^{18,19}$

\section{Prognosis and natural history}

A large study involving >5,000 patients with WM from 1991 to 2010 showed that the median OS for the entire cohort was 7 years and the 5- and 10 -year OS were $62 \%$ and $39 \%$, respectively. ${ }^{2}$ The 5-year OS for patients who were diagnosed prior to the age of 70 years compared to those older than 70 years was $71 \%$ and $39 \%$, respectively. ${ }^{4}$ The OS has increased over the last two decades; the median OS for the patients diagnosed between 1991 and 2000 was 6 vs 8.2 years for those diagnosed between 2001 and 2010, $P<0.05 .2,20$

\section{Smoldering WM}

At the time of diagnosis, $\sim 25 \%$ of patients with $\mathrm{WM}$ do not have symptoms or signs that are attributable to an increased monoclonal protein or infiltration by malignant cells. This population of patients is considered to have smoldering WM, and there are no indications for the initiation of treatment until the development of symptoms or significant anemia/thrombocytopenia in this patient population given the risks involved and the lack of survival advantage with early treatment. ${ }^{21}$ The OS rate of patients with smoldering WM can approximate that of the normal age-matched population. ${ }^{8}$ A Mayo Clinic study demonstrated that the rate of progression of patients with smoldering WM to symptomatic WM during a 15-year follow-up was $71 \%$, and the cumulative risk of progression of smoldering WM to symptomatic WM, amyloidosis, or a related disorder was $6 \%$ at 1 year, $39 \%$ at 3 years, $59 \%$ at 5 years, and $68 \%$ at 10 years. ${ }^{22}$

\section{Prognosis}

The International Prognostic Symptom Score (IPSS) for WM was created to assess the disease prognosis and survival risk in patients with active $\mathrm{WM}$ who require treatment (Table 3 ). ${ }^{23}$

\section{Treatment}

The optimal initial approach requires assessment of the symptomatology, the genetic signature, ie, MYD 88 status (CXCR4 status is not routinely used in practice at present), the monoclonal protein size, age of the patient, and certain laboratory parameters. The decision to commence therapy typically should not be based on the size of serum IgM size. ${ }^{24}$ The treatment indications for symptomatic patients are outlined in Table $4 . .^{21,24,25}$

Furthermore, the therapy-related decisions depend on the rapidity with which the symptom control is necessary. Hyperviscosity-related symptoms warrant urgent plasmapheresis..$^{25,26}$ Other indications that require immediate reduction in IgM protein include moderate-to-severe hemolytic anemia, bulky lymphadenopathy, and symptomatic cryoglobulinemia. 
Table 3 Disease prognosis based on IPSS

\begin{tabular}{|c|c|}
\hline Prognostic factors & Cutoffs at which the factor is considered adverse at the time of initiation of treatment \\
\hline Age & $\geq 65$ years \\
\hline Hemoglobin & $\leq 11.5 \mathrm{~g} / \mathrm{dL}$ \\
\hline Platelets & $\leq 100 \times 10^{9} / \mathrm{L}$ \\
\hline ß2-Microglobulin & $>3 \mathrm{mg} / \mathrm{L}$ \\
\hline Serum monoclonal IgM & $>7 \mathrm{~g} / \mathrm{dL}$ \\
\hline Risk stratification & 5-Year survival (\%) \\
\hline Low & $\leq \mathrm{I}$ adverse variable (except age) \\
\hline Intermediate & 2 adverse variables or age $>65$ years \\
\hline High & $>2$ adverse variables \\
\hline
\end{tabular}

Abbreviations: IgM, immunoglobulin M; IPSS, International Prognostic Symptom Score.

Table 4 Treatment indications for symptomatic patients

\begin{tabular}{ll}
\hline Clinical indications & Laboratory indications \\
\hline $\begin{array}{l}\text { Signs and symptoms associated with } \\
\text { hyperviscosity }\end{array}$ & Hemoglobin $<10 \mathrm{~g} / \mathrm{dL}$ \\
$\begin{array}{l}\text { Moderate to severe peripheral } \\
\text { neuropathy }\end{array}$ & Platelet count $<100 \times 10^{9} / \mathrm{dL}$ \\
AL amyloidosis & Hemolytic anemia \\
$\begin{array}{l}\text { Symptomatic cryoglobulinemia } \\
\text { Constitutional symptoms, Raynaud's } \\
\text { phenomenon, and arthralgia }\end{array}$ & \\
Bulky or symptomatic lymphadenopathy & \\
Symptomatic organomegaly & \\
\hline Abbreviation: AL amyloid light-chain.
\end{tabular}

Abbreviation: AL, amyloid light-chain.

\section{Immunotherapy}

Rituximab, a chimeric anti-CD20 monoclonal antibody, serves as a backbone of therapy directed against $\mathrm{CD} 20^{+}$ WM cells. ${ }^{27-29}$ The two important side effects include IgM flare and late-onset neutropenia (LON). IgM flare (defined as a transient increase in IgM levels by at least $25 \%$ from the baseline pretreatment levels) is generally seen in patients with serum IgM levels $>4 \mathrm{~g} / \mathrm{dL}$. It is typically encountered in the first month of rituximab therapy but at times can persist for several months. ${ }^{30}$ In patients with hyperviscosity symptoms and IgM $>4 \mathrm{~g} / \mathrm{dL}$, preemptive plasmapheresis and avoidance of rituximab during the first $1-2$ cycles is recommended. ${ }^{31,32}$ LON is a poorly understood complication of rituximab with a speculated correlation to FcR $\gamma \mathrm{IIIa}-\mathrm{V} 158^{*} \mathrm{~F}$ polymorphism secondary to profound antibody-dependent cell-mediated cytotoxicity activity and pronounced B-cell depletion associated with this polymorphism, causing neutrophil destruction by the release of granzyme and lysozyme. ${ }^{33-36}$ Ofatumumab, a fully human anti-CD20 antibody, targets an epitope that is different from that of rituximab. It may be used in patients who are intolerant of rituximab, but higher cost and the lack of data suggesting superiority over rituximab restrict its use. ${ }^{37,38}$

\section{Chemoimmunotherapy}

Alkylator-based combination therapy has been considered highly effective in WM. Dexamethasone and rituximab in combination with cyclophosphamide (DRC) is a commonly prescribed regimen. Adriamycin and vincristine are avoided in WM owing to significant side effects without substantial additional benefit. ${ }^{39}$ The DRC regimen is unsuitable for rapid control of symptoms as the median time to response is 4.1 months. ${ }^{40}$ The 8-year OS rates in IPSS for WM low-, intermediate- and high-risk patients have been reported to be $100 \%, 55 \%$, and $27 \%$, respectively. The median progressionfree survival (PFS) with DRC is 35 months $(95 \% \mathrm{CI}$ : 22-48 months). Patients who relapse after DRC are found to be still sensitive to rituximab. The regimen appears to be safe in both short and long terms..$^{40,41}$

A subset analysis of a Phase III, open-label trial by Rummel et al, comparing bendamustine in combination with rituximab (BR) with rituximab, cyclophosphamide, doxorubicin, vincristine, and prednisone (R-CHOP), showed a markedly improved median PFS with BR (69.5 [36.6-73] months vs 28.1 [17.8-51] months with R-CHOP). Both regimens led to an overall response rate (ORR) that approximated $95 \%$. The patients who received BR tolerated therapy better, with lower rates of high-grade neutropenia, infectious complications, peripheral neuropathy, and absence of alopecia. ${ }^{42}$ Of note, patients with severe functional defects of the organ dysfunction (NYHA III or IV, creatinine $>2 \mathrm{mg} / \mathrm{dL}$, aspartate aminotransferase/alanine aminotransferase/bilirubin $>3 \times$ upper limit of normal) were excluded..$^{42}$ Due to the superior tolerability of $\mathrm{BR}$, the Mayo Clinic group suggests using BR as the front-line option in patients with symptomatic WM. ${ }^{7}$ Comparable results, with an ORR of $80 \%$ and $83 \%$, were reported in two retrospective studies involving relapsed/refractory WM patients treated with BR. ${ }^{43,44}$ Prolonged cytopenias are frequent in patients receiving BR who have previously received nucleoside analog therapy. ${ }^{44}$ Truncation of BR therapy from six to four cycles 
to avoid the prolonged cytopenias is not uncommon owing to comparable efficacy. ${ }^{45}$ Reduction of the dose from 90 to $60-70 \mathrm{mg} / \mathrm{m}^{2}$ in the elderly and those with compromised renal function is also a common practice. ${ }^{39}$

A survival benefit with nucleoside analog in WM was demonstrated in a multicenter Phase III randomized WM1 trial (trial comparing chlorambucil with fludarabine in patients with advanced WM). Oral fludarabine in comparison to chlorambucil resulted in a significantly longer PFS (36 vs 27 months; $P=0.012$ ) and $\mathrm{OS}$ (not reached vs 70 months; $P=0.014$ ), with a longer duration of response (38 vs 20 months; $P<0.001$ ). ${ }^{46}$ In this study, myelodysplastic syndrome and acute myeloid leukemia (MDS/AML) developed in $\sim 1.5 \%$ in the chlorambucil arm, but surprisingly, this complication was not observed in the fludarabine-treated patients. ${ }^{46}$ Despite being highly effective, nucleoside analogs are less preferred now in the frontline setting owing to the risk of second malignancies. ${ }^{39,47}$ Because nucleoside analogs can also adversely impact stemcell mobilization, they are best avoided as frontline therapies in the transplant-eligible patients. We typically reserve the use of nucleoside analogs for the relapsed-refractory population.

The proteasome inhibitors are among the most effective therapies in WM, particularly when combined with a steroid and rituximab. ${ }^{48,49}$ In the initial trial by the Waldenström's Macroglobulinemia Clinical Trials Group (WMCTG) using this combination in 23 treatment-naive WM patients, the ORR was $96 \%$, with a median time to response of 1.4 months. The rapid response prompted physicians to use this combination in patients with hyperviscosity syndromes. ${ }^{50}$ Strikingly, despite substantial response, $60 \%$ of patients discontinued therapy after four cycles due to severe neuropathy. Investigators have attempted to reduce the incidence of treatmentemergent neuropathy by switching to weekly administration (three doses per cycle, $\mathrm{D}_{1,8,15}$ ) or using subcutaneous doses (NCT01788020). Preliminary data show that subcutaneous bortezomib in combination with rituximab and cyclophosphamide is quite effective. ${ }^{51}$ Bortezomib-based therapy may be considered in patients with severe symptoms requiring rapid decrease in the monoclonal protein. Bortezomib is nonmyelotoxic and, therefore, can potentially be also used for maintenance therapy in patients without neuropathy, although clinicians should be vigilant about treatmentemergent neuropathy. An antiviral prophylaxis is required for the prevention of herpes zoster. A novel combination of carfilzomib, rituximab, and dexamethasone (CaRD) used as a neuropathy-sparing regimen in patients with WM led to $87 \%$ ORR and $36 \%$ VGPR when used as frontline therapy. ${ }^{52}$ Other novel proteosome inhibitors that are being investigated include oprozomib (an oral epoxyketone irreversible proteasome inhibitor) and ixazomib (an oral boronic acid-based reversible proteasome inhibitor)..$^{39,53-55}$

\section{Immunomodulatory drugs (IMiDs)}

The use of IMiDs has been attempted in WM, given their impressive activity in MM. Thalidomide has been shown to be quite effective in WM. ${ }^{56-59}$ Coleman et al ${ }^{57}$ reported its use in patients previously treated with a purine analog or alkylating agent in combination with clarithromycin and dexamethasone. This combination was suggested as a salvage regimen in heavily pretreated patients. ${ }^{59}$ Thalidomide in combination with rituximab led to an ORR of $72 \%{ }^{58}$ The major disadvantage was the high incidence of neurotoxicity and poor tolerability by elderly patients. ${ }^{56-59}$ Lenalidomide has been evaluated in Phase I and II trials in the setting of WM. Due to the dose limiting toxicity at $20 \mathrm{mg}$, a dose of $15 \mathrm{mg}$ was used for 21 of 28 days. At a median follow-up of 36 months, the time to progression (TTP) was 16 months and the 5-year OS was $91 \%$. Combination of lenalidomide and rituximab led to abrupt decrease in hemoglobin in $88 \%$ of the patients. ${ }^{60}$ Investigators also evaluated the combination of pomalidomide with dexamethasone and rituximab (NCT01078974) in a dose-escalating Phase I study in seven patients, with a median time to response of 2.1 months and a median response duration of 15 months. A substantial proportion of patients (3/7) required plasmapheresis for IgM flare due to which the study was prematurely terminated. Given these issues, IMiDs have not been considered particularly attractive in WM.

\section{Other agents}

Everolimus, an inhibitor of mechanistic (formerly mammalian) target of rapamycin (mTOR) was studied in 60 relapsed/ refractory patients with WM. The median time to remission was 2 months with a median PFS of 4 months. Major remission and partial remission were noted in $23 \%$ and $50 \%$ of the patients, respectively, with $23 \%$ developing grade $3 / 4$ cytopenias. ${ }^{61}$ The use of everolimus was also attempted in treatment-naive patients of WM with an ORR of $66.7 \%$ and major responses of $42.4 \% .{ }^{62}$ Severe adverse events included significant cytopenias, oral ulceration (prevented by dexamethasone swashes), and pulmonary toxicity. Everolimus has been tried in combination with bortezomib and rituximab (RVR), demonstrating a median PFS of 21 months. ${ }^{63}$

Idelalisib targets the PI3K pathway, which is activated in patient with MYD88 mutation. de Rooij et al described the inhibition of WM cells' proliferation by idelalisib. They also suggested that both idelalisib and ibrutinib dislodge the 
WM cells from the microenvironment into the circulation, which leads to the death of these cells in the absence of a supportive niche. ${ }^{64}$ Recently, a Phase II study evaluating the safety and efficacy of idelalisib in patients with relapsed and/or refractory symptomatic WM was prematurely closed owing to the high incidence of hepatotoxicity. ${ }^{65}$ Sildenafil, a phosphodiesterase inhibitor, was serendipitously found to be effective after an unusual response in the disease status of five WM patients following the prescription of sildenafil for erectile dysfunction. ${ }^{66}$ Table 5 summarizes the dosing schedules and outcomes of rituximab treatment as monotherapy and as combination therapy when combined with various abovementioned treatment regimens.

\section{Role of ibrutinib in the management of WM}

Ibrutinib, an oral BTK inhibitor, acts by inhibiting downstream signaling of B-cell receptor pathway. By impairing crosstalk between MYD88 and BTK, it induces apoptosis of WM cells. ${ }^{67}$ Additionally, it has a role in inhibiting hematopoietic cell kinase (HCK) as described below in detail.
The important pharmacological aspects of ibrutinib and the various clinical trials conducted to date to evaluate its role in WM are tabulated in Tables 6 and 7, respectively.

\section{Ibrutinib as monotherapy}

The first Phase II multicenter clinical trial to show the efficacy of ibrutinib in relapsed-refractory WM ( $\geq 1$ prior therapy) was NCT01614821 that led to this agent's approval in WM in the US, Europe, and Canada. The population studied had received a median of two lines of therapy (range: 1-9 lines), with a median BM involvement of 60\% (3-95\%). IgM decreased rapidly as suggested by a median time to partial response of 8 weeks and the achievement of minimal responses as early as 4 weeks from the start of therapy. ${ }^{68}$ The best clinical responses to ibrutinib at a median duration of treatment of 19 months (0.5-29.7 months) were an ORR of $91 \%$ and a major response rate of $73 \%$. Complete response (CR) with ibrutinib monotherapy was strikingly absent. The short follow-up showed a 2-year PFS and an OS of $69.1 \%$ and $95.2 \%$, respectively. ${ }^{68}$ Ibrutinib monotherapy has also been evaluated as a part of the iNNOVATE ${ }^{\mathrm{TM}}$ study in patients refractory to rituximab.

Table 5 Various regimens with rituximab in WM

\begin{tabular}{|c|c|c|c|}
\hline Regimen & Schedule & Responses & TTP/PFS \\
\hline $\begin{array}{l}\text { Rituximab monotherapy - standard } \\
\text { dosing }^{27-29}\end{array}$ & $375 \mathrm{mg} / \mathrm{m}^{2} \times 4$ weekly doses & $\begin{array}{l}\text { ORR: } 30-60 \% \text {; VGPR/CR: } \\
0-5 \%\end{array}$ & DOR: 8-II months \\
\hline $\begin{array}{l}\text { Rituximab monotherapy - extended } \\
\text { schedule }^{27-29}\end{array}$ & $\begin{array}{l}375 \mathrm{mg} / \mathrm{m}^{2} \times 4 \text { weekly doses (weeks I-4) + repeat } \\
4 \text { weekly doses (weeks I2-16) }\end{array}$ & $\begin{array}{l}\text { ORR: } 35-45 \% \text {; VGPR/CR: } \\
5-10 \%\end{array}$ & DOR: 16-29 months \\
\hline Ofatumumab monotherapy ${ }^{38}$ & $\begin{array}{l}300 \mathrm{mg} \text { for weeks I to } 2-4 \text { with either standard } \\
\text { dose: I g/week or high dose: } 2 \text { g/week in patients } \\
\text { with minor response/stable disease - week I6: } \\
300 \mathrm{mg} \rightarrow 2 \mathrm{~g} / \text { week } \times 4 \text { weeks (weeks I7-20) }\end{array}$ & $\begin{array}{l}\text { ORR: } 59 \% \text {; major response: } \\
35 \%\end{array}$ & \\
\hline Rituximab + alkylator (DRC) ${ }^{40}$ & $\begin{array}{l}\text { Dexamethasone } 20 \mathrm{mg} \text { IV } \rightarrow \text { rituximab } 375 \mathrm{mg} / \mathrm{m}^{2} \\
\text { IV on } D_{1} \text { and cyclophosphamide } 100 \mathrm{mg} / \mathrm{m}^{2} \text { orally } \\
\text { bid on } D_{1-5}\left(\text { total dose, } 1,000 \mathrm{mg} / \mathrm{m}^{2}\right) \text { every } 21 \text { days } \\
\times 6 \text { cycles }\end{array}$ & $\begin{array}{l}\text { ORR: } 83 \% \text {; major response: } \\
74 \%\end{array}$ & Median PFS: 35 months \\
\hline $\begin{array}{l}\text { Rituximab + alkylator } \\
\text { (bendamustine) }{ }^{42}\end{array}$ & $\begin{array}{l}90 \mathrm{mg} / \mathrm{m}^{2} \text { bendamustine } D_{1} / D_{2} ; 375 \mathrm{mg} / \mathrm{m}^{2} \text { rituximab } \\
\text { on } D_{1} \text { repeated every } 4 \text { weeks } \times 6 \text { cycles }\end{array}$ & ORR: $95 \%$ & PFS: 69.5 months \\
\hline $\begin{array}{l}\text { Rituximab + proteosome inhibitor } \\
\text { (bortezomib - BDR) })^{50}\end{array}$ & $\begin{array}{l}\text { Bortezomib - I. } 3 \mathrm{mg} / \mathrm{m}^{2} \mathrm{IV}-\mathrm{D}_{\mathrm{I}, 4,8,1} ; \\
\text { dexamethasone }-40 \mathrm{mg} \text { IV }-\mathrm{D}_{\mathrm{I}, 4,8, \mathrm{I}} ; \text { rituximab } \\
-375 \mathrm{mg} / \mathrm{m}^{2} \mathrm{IV}-\mathrm{D}_{\mathrm{II}} \text { every } 2 \mathrm{I} \text { days } \times 4 \text { cycles } \\
\text { of induction and } 4 \text { cycles from } 3 \text { months as } \\
\text { maintenance }\end{array}$ & $\begin{array}{l}\text { ORR: } 96 \% \text {; major } \\
\text { responses: } 83 \%\end{array}$ & Median PFS: 66 months \\
\hline $\begin{array}{l}\text { Rituximab + proteosome inhibitor } \\
(\text { carfilzomib - CaRD) })^{52}\end{array}$ & $\begin{array}{l}\text { Carfilzomib }\left(20 \mathrm{mg} / \mathrm{m}^{2}-\text { cycle: } \mathrm{I}, 36 \mathrm{mg} / \mathrm{m}^{2}-\text { cycles: }\right. \\
2-6) \text {; rituximab }\left(375 \mathrm{mg} / \mathrm{m}^{2}, \mathrm{D}_{2,9}\right) \text {; dexamethasone } \\
\left(20 \mathrm{mg}, \mathrm{D}_{1,2,8,9}\right) \text { every } 2 \mathrm{I} \text { days } \times 6 \text { cycles }\end{array}$ & CR: $87 \%$; VGPR: $36 \%$ & Median PFS: $>16$ months \\
\hline Rituximab + IMiD 60 & $\begin{array}{l}\text { Rituximab ( } 375 \mathrm{mg} / \mathrm{m}^{2} \text {, weekly on weeks } 2-5 \text { and } \\
\mathrm{I} 3-\mathrm{l} 6) \text { and len } 25 \mathrm{mg} \text { for } 2 \mathrm{I} / 28 \text { days }\end{array}$ & $\begin{array}{l}\text { ORR: } 50 \% \text { (abrupt decrease } \\
\text { in } \mathrm{Hgb} \text { in } 88 \% \text { of patients) }\end{array}$ & $\begin{array}{l}\text { Median TTP: } \\
\text { I7.I months }\end{array}$ \\
\hline $\begin{array}{l}\text { Rituximab }+ \text { mTOR inhibitor }+ \\
\text { bortezomib }^{63}\end{array}$ & $\begin{array}{l}\text { Everolimus - I0 mg PO daily; bortezomib I. } 6 \mathrm{mg} / \\
\mathrm{m}^{2} \mathrm{IV}_{\mathrm{I}, 8,15} \text { for } 28 \text { days/cycle } \times \text { six cycles; rituximab } \\
375 \mathrm{mg} / \mathrm{m}^{2} \text { IV } D_{1,8,15,22}-\text { cycles I and } 4 \text { only }\end{array}$ & ORR: $89 \%$ & Median PFS: 21 months \\
\hline
\end{tabular}

Abbreviations: BDR, bortezomib dexamethasone rituximab; CaRD, carfilzomib, rituximab and dexamethasone; CR, complete response; D, dexamethasone; DOR, duration of response; DRC, dexamethasone and rituximab in combination with cyclophosphamide; Hgb, hemoglobin; IMiD, immunomodulatory drug; IV, intravenous; Len, lenalidomide; mTOR, mechanistic target of rapamycin; ORR, overall response rate; PFS, progression-free survival; PO, oral; TTP, time to progression; VGPR, very good partial response; WM, Waldenström macroglobulinemia. 
Table 6 Aide memoirs on ibrutinib

\begin{tabular}{|c|c|c|}
\hline Pharmacokinetics & Dose modifications & Interactions \\
\hline $\begin{array}{l}\text { - A BTK inhibitor } \\
\text { - } t \mathrm{t} / 2-2-3 \mathrm{~h} \\
\text { - Oral bioavailability - good } \\
\text { - Peak plasma levels - I-2 } \mathrm{h} \\
\text { - Clearance - liver metabolism by CYP3A } \\
\text { - Elimination } t \mathrm{I} / 2-4-6 \mathrm{~h}\end{array}$ & $\begin{array}{l}\text { - Renal modification } \\
\text { - No modification required } \\
\text { - Monitor toxicities } \\
\text { - Hepatic modification based on Child-Pugh } \\
\text { classification } \\
\text { - Class A - } \downarrow \text { to once daily } \\
\text { - Classes B and C - avoid usage }\end{array}$ & $\begin{array}{l}\text { - CYP3A inducers }-\downarrow \text { plasma level } \\
\text { - Antiepileptics: carbamazepine and } \\
\text { phenytoin } \\
\text { - Antitubercular: rifampin } \\
\text { - St John's wort } \\
\text { - CYP3A inhibitors - } \uparrow \text { plasma level } \\
\text { - Antivirals (protease inhibitors) } \\
\text { - Antifungals (azoles) } \\
\text { - Macrolides } \\
\text { - Food interactions: avoid } \\
\text { - Seville orange } \\
\text { - Starfruit } \\
\text { - Grapefruit juice }\end{array}$ \\
\hline Special category of population & Dosage & Side effects \\
\hline $\begin{array}{l}\text { - Pregnancy - avoid pregnancy for I month after } \\
\text { cessation of therapy } \\
\text { - Males - avoid fathering for I month after } \\
\text { cessation of therapy } \\
\text { - Breast feeding - not studied; decision based on } \\
\text { the risk-benefit ratio for the mother's health } \\
\text { vis-à-vis exposure to newborn } \\
\text { - Surgery - withhold 3-7 days before and after } \\
\text { surgery depending on the bleeding risk involved } \\
\text { with the surgery }\end{array}$ & $\begin{array}{l}\text { - Capsule strength - } 140 \mathrm{mg} \\
\text { - Dose - three tablets per day } \\
\text { - Timing with regard to food intake - no bearing } \\
\text { on the bioavailability } \\
\text { - Missed dosing - to take capsule as soon as the } \\
\text { patient remembers in the same day; no additional } \\
\text { dosing on subsequent day recommended for } \\
\text { missed doses }\end{array}$ & $\begin{array}{l}\text { - Bleeding } \\
\text { - Platelet dysfunction } \\
\text { - Aggravation of avWD secondary } \\
\text { - Atrial fibrillation, hyper/hypotension } \\
\text { - Headache and dizziness } \\
\text { - Cytopenias } \\
\text { - Infections } \\
\text { - Gastrointestinal disturbances } \\
\text { - Fatigue, musculoskeletal pain, and } \\
\text { arthralgias }\end{array}$ \\
\hline
\end{tabular}

Abbreviations: avWD, acquired von Willebrand's disease; BTK, Bruton's tyrosine kinase.

Table 7 Studies using ibrutinib monotherapy in WM

\begin{tabular}{|c|c|c|c|c|}
\hline Reference & Type of study & Sample size & Disease setting & Outcome \\
\hline Advani et al ${ }^{91}$ & Phase I & $4^{a}$ & $\mathrm{RR}$ & $\begin{array}{l}75 \% \text { achieved response and continued to have } \\
\text { response at } 4 \text { years }\end{array}$ \\
\hline Treon et $\mathrm{a}^{68}$ & Phase II & 63 & $\mathrm{RR}$ & $\begin{array}{l}\text { ORR }-95 \% \\
\text { OS }-95 \% \text { at } 2 \text { years } \\
\text { PFS }-69 \% \text { at } 2 \text { years }\end{array}$ \\
\hline $\begin{array}{l}\text { Dimopoulos et al, }{ }^{69} \\
\text { iNNOVATE }^{\text {TM }}\end{array}$ & Phase III & 31 & $\begin{array}{l}\text { Refractory to last rituximab } \\
\text { containing therapy }\end{array}$ & $\begin{array}{l}\text { ORR }-90 \% \\
\text { OS }-92 \% \text { at } 18 \text { months } \\
\text { PFS }-86 \% \text { at } 18 \text { months }\end{array}$ \\
\hline
\end{tabular}

Note: a Out of total 56 patients of CLL/NHL.

Abbreviations: CLL, chronic lymphocytic leukemia; NHL, non-Hodgkin lymphoma; ORR, overall response rate; OS, overall survival; PFS, progression-free survival; RR, relapsed and/or refractory; WM, Waldenström macroglobulinemia.

The therapy was effective with a high ORR of $90 \%$ and an estimated 18-month OS of $97 \%$ and PFS of $86 \%$ (Table 7). The median time to best response was 2 months. ${ }^{69}$ Adverse events included grade 1-2 thrombocytopenia (13\%) and diarrhea (36\%) and grade 3 neutropenia $(10 \%)$ and hypertension $(10 \%)$. A vast majority of serious adverse events were related to infections. ${ }^{69}$

\section{Effect of mutations on the efficacy of ibrutinib}

CXCR4 mutations confer resistance to ibrutinib. In vitro studies of the $C X C R 4^{\text {WHIM }}$-engineered WM cells demonstrated that the presence of a mutation in the CXCR4 gene of the cells decreases their apoptosis following CXCL12 stimulation owing to the persistent activation of AKT and extracellular signal-regulated kinases. ${ }^{70}$ These survival effects of $C X C R 4^{\text {WHIM }}$ mutation are abrogated by the inhibition of simultaneous MYD88 ${ }^{\mathrm{L} 265 \mathrm{P}}$ signaling. ${ }^{71}$ Treon et al ${ }^{72}$ have demonstrated significant differences in response rates (ORR and major response rate) in patients with $M Y D 88^{\mathrm{L} 265 \mathrm{P}} / C X C R 4^{\mathrm{WT}}$, $M Y D 88^{\mathrm{L} 265 \mathrm{P}} / C X C R 4^{\mathrm{WHIM}}$, and $M Y D 88^{\mathrm{WT}}$ mutations; the major response rate was $62 \%$ in patients with mutated MYD 88 and CXCR4 ${ }^{\text {WHIM }}$ gene and $92 \%$ in those with mutated MYD 88 and $C X C R 4^{\mathrm{WT}}$ gene, whereas no major response was observed in patients with $M Y D 88^{\mathrm{WT}} C X C R 4^{\mathrm{WT}}$ genotype. Of the arm C study population $(n=31)$ of the iNNOVATE trial, 25 patients 
underwent mutation analysis, of which $M Y D 88^{\mathrm{L} 265 \mathrm{P}} / C X C R 4^{\mathrm{WT}}$

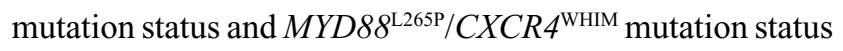
were seen in 17 and 7 patients, respectively ${ }^{69}$ Though this study was not powered to assess the differences of treatment response with respect to mutation status, major response was seen in $82 \%$ of patients with $M Y D 88^{\mathrm{L} 265 \mathrm{P}} / C X C R 4^{\mathrm{WT}}$ genotype and $71 \%$ of patients with $M Y D 88^{\mathrm{L} 265 \mathrm{P}} / C X C R 4^{\mathrm{WHIM}}$ genotype. ${ }^{69}$ IgM reduction was greater and achieved earlier in patients

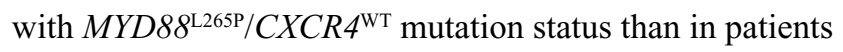
with MYD $88^{\mathrm{L} 265 \mathrm{P}} / C X C R 4^{\mathrm{WHIM}}$ mutation status. ${ }^{69}$ Therefore, for ibrutinib-treated patients with WM, the MYD $88^{\mathrm{L} 265 \mathrm{P}}$ mutation serves as a favorable prognostic marker, while the CXCR4 mutation is a predictive marker, and it is reasonable to check for the presence of MYD $88^{\mathrm{L} 265 \mathrm{P}}$ mutation prior to subjecting a patient to indefinite ibrutinib therapy, ie, until progression or intolerable side effects. ${ }^{7}$

\section{Adverse effects of ibrutinib}

Adverse events include cytopenias, infections, arrhythmias, and bleeding (particularly epistaxis). Previously treated patients with WM were more likely to experience cytopenias with ibrutinib.

A tenfold increase in the risk of atrial fibrillation (AFib) in the ibrutinib arm was first noticed in the randomized Phase III open-label RESONATE study comparing ibrutinib and ofatumumab in 391 refractory CLL/SLL patients. ${ }^{73}$ A metaanalysis to evaluate the risk of AFib in patients on ibrutinib vs the comparator drug/arm in random and fixed effects models showed a relative risk of 3.5 and 3.9, respectively. The rate of AFib on pooled analysis of the 20 studies was 3.3 per 100 person years. ${ }^{74}$ Gustine et $\mathrm{al}^{75}$ reported the cumulative risk of AFib of 5.4, 7.1, and 8.9\% in $112 \mathrm{WM}$ patients on ibrutinib at 1, 2, and 3 years, respectively. A past history of AFib leads to a shorter recurrence time of 3.9 vs 33.4 months in otherwise asymptomatic patients, and dose reduction and cardiologic intervention allowed the patients to continue therapy. ${ }^{75}$ Ibrutinib should be avoided in patients with AFib on anticoagulation. ${ }^{25}$ Animal experiments have suggested a role of ibrutinib in the inhibition of the cardiac PI3K-AKT signaling as the cause of the development of AFib. ${ }^{76}$ Although a decrease in QTc interval is another potential cardiac side effect with ibrutinib, its significance is unclear. Ibrutinib also leads to platelet aggregation abnormalities and is best avoided in patients concurrently on other antiplatelet agents that have a potential to cause bleeding diathesis/platelet dysfunction. ${ }^{77}$ This off-target effect was first observed in CLL trials. Acquired von Willebrand's disease (aVWD) can be infrequently encountered in WM patients $(\sim 5 \%)$ due to elevated IgM levels. ${ }^{78}$ Therefore, it is reasonable to check aVWD levels/activity prior to commencing ibrutinib in WM patients with a history of bleeding. ${ }^{25}$

\section{Experimental combinations of ibrutinib with novel agents}

The aforementioned multicenter study (iNNOVATE; NCT02165397) began enrollment in July 2014 in 51 centers across the world to study the role of ibrutinib in combination with rituximab. This is primarily a randomized controlled trial wherein patients receive rituximab (4 weekly doses of $375 \mathrm{mg} / \mathrm{m}^{2} \mathrm{IV}$, with repeat 4 weekly doses after 3 months), with or without ibrutinib $420 \mathrm{mg}$ daily until progression or unacceptable toxicity. WM patients who are treatment naive as well as those with documented progression and no response to their most recent treatment regimen were included in the study. Those patients who were refractory to rituximab-containing regimen were excluded from randomization but studied separately in an open-label arm with single-agent ibrutinib, the results of which were discussed earlier (Table 7).

IRAK1 is another protein downstream of BTK, which can contribute to the WM cell survival after exposure to ibrutinib. WM cells with MYD88 mutation show preferential IRAK1 rather than IRAK4 signaling. A combination therapy of ibrutinib with IRAK inhibitors can potentially augment the NFK $\beta$ blockade and theoretically overcome ibrutinib resistance. ${ }^{79}$

Yang et al have demonstrated the overexpression of hemopoietic cell kinase (HCK) in WM cell lines with MYD88 $8^{\mathrm{L} 265 \mathrm{P}}$ mutation based on transcriptome profiling. The efficacy of ibrutinib in WM cell lines with $M Y D 88^{\mathrm{L} 265 \mathrm{P}}$ mutation was directly correlated to its binding to HCK, whereas mutated HCK blocked ibrutinib-related tumor cell killing. This study implicated the HCK pathway for ibrutinib resistance and a novel target in patients with MYD88 mutation. ${ }^{80,81}$

B-cell CLL/lymphoma 2 (BCL2) antagonist, venetoclax, is effective in WM with $C X C R 4^{W H I M}$ mutation that is known to cause resistance to BTK and PI3K inhibitors. A study on the cell lines derived from WM patients with $C X C R 4^{\text {WHIM }}$ mutations showed enhanced apoptosis with ibrutinib and idelalisib in the presence of venetoclax. Activity of venetoclax as a single agent has also been demonstrated in cell lines with $C X C R 4^{\mathrm{WT}}$ mutations and is postulated to be due to overexpression of BCL2 by the WM cells. ${ }^{82}$ Aurora kinase inhibitors have also been proposed for therapy in patients exhibiting ibrutinib resistance. ${ }^{83}$ 


\section{Role of stem cell transplant in WM}

Autologous stem cell transplant (ASCT) is a therapeutic consideration for the young patients with relapsed disease. Patients who are considered eligible for transplantation should avoid induction with drugs that are stem cell toxic. ${ }^{7,39}$ The European Bone Marrow Transplant Registry (EBMTR) data on 158 patients who underwent ASCT for WM suggest a 5 -year OS of $69 \%$ and a PFS of $49 \%$, with nonrelapse mortality (NRM) of 5.6\% ${ }^{86}$ Patients undergoing transplant in the first remission had a significantly superior outcome as compared to those undergoing ASCT at a later time (5-year disease-free survival [DFS] of $50 \%$ vs $40 \% ; P=0.004$, and 5 -year OS of $71 \%$ vs $63 \% ; P=0.033){ }^{84,85}$

Allogeneic hematopoietic stem cell transplant (allo-SCT) has a very limited role, given the high transplant-related mortality, and we do not recommend this approach outside of clinical trials. Some experts suggest restricting its use primarily to young patients with multiple relapsed-refractory disease and particularly to those with early relapse post-ASCT. The reported ORR was $76 \%$, the 5 -year PFS was $56 \%$, and the OS was $62 \%$ in a cohort of 86 patients. Twenty percent of patients achieved CR with allo-SCT. The 3-year NRM was $33 \%$ in patients receiving full myeloablative conditioning and $23 \%$ in patients receiving reduced-intensity conditioning. ${ }^{86}$

\section{Conclusion}

With the introduction of molecular prognostic markers and improved understanding of the role of MYD 88 and CXCR mutations in the pathophysiology of WM, the field appears to be rapidly evolving. The efficacy of multiple new agents including the second-generation BTK inhibitor (acalabrutinib), BCL2 inhibitors, IRAK inhibitors, and monoclonal antibodies, such as belimumab (anti-Blys) and ulocuplumab (anti-CXCR4), is being evaluated. Given the remarkable strides that have been made recently in our understanding of this rare malignancy, we suspect that the treatment options are bound to improve in the coming years, albeit at the cost of making its management increasingly complex.

\section{Disclosure}

Research funding has been provided to the institution from Celgene, Takeda and Amgen for studies, in which Prashant Kapoor is a principal investigator. The authors report no other conflicts of interest in this work.

\section{References}

1. Waldenström J. Incipient myelomatosis or essential hyperglobulinemia with fibrinogenopenia - a new syndrome? J Intern Med. 1944; $117(3-4): 216-247$.
2. Castillo JJ, Olszewski AJ, Kanan S, Meid K, Hunter ZR, Treon SP. Overall survival and competing risks of death in patients with Waldenstrom macroglobulinaemia: an analysis of the Surveillance, Epidemiology and End Results database. Br J Haematol. 2015;169(1):81-89.

3. Kristinsson SY, Eloranta S, Dickman PW, et al. Patterns of survival in lymphoplasmacytic lymphoma/Waldenstrom macroglobulinemia: a population-based study of 1,555 patients diagnosed in Sweden from 1980 to 2005. Am J Hematol. 2013;88(1):60-65.

4. Sekhar J, Sanfilippo K, Zhang Q, Trinkaus K, Vij R, Morgensztern D. Waldenstrom macroglobulinemia: a Surveillance, Epidemiology, and End Results database review from 1988 to 2005. Leuk Lymphoma. 2012;53(8):1625-1626.

5. Olszewski AJ, Treon SP, Castillo JJ. Evolution of management and outcomes in Waldenstrom macroglobulinemia: a population-based analysis. Oncologist. Epub 2016 Jul 29.

6. Kristinsson SY, Bjorkholm M, Goldin LR, McMaster ML, Turesson I, Landgren O. Risk of lymphoproliferative disorders among first-degree relatives of lymphoplasmacytic lymphoma/Waldenstrom macroglobulinemia patients: a population-based study in Sweden. Blood. 2008;112(8):3052-3056.

7. Kapoor P. Diagnosis and management of Waldenstrom macroglobulinemia mayo stratification of macroglobulinemia and risk-adapted therapy (mSMART) guidelines. JAMA Oncol. Epub 2017 Jan 5.

8. Ansell SM, Kyle RA, Reeder CB, et al. Diagnosis and management of Waldenstrom macroglobulinemia: mayo stratification of macroglobulinemia and risk-adapted therapy (mSMART) guidelines. Mayo Clin Proc. 2010;85(9):824-833.

9. Landgren O, Tageja N. MYD88 and beyond: novel opportunities for diagnosis, prognosis and treatment in Waldenstrom's macroglobulinemia. Leukemia. 2014;28(9):1799-1803.

10. Treon SP, Xu L, Yang G, et al. MYD88 L265P somatic mutation in Waldenstrom's macroglobulinemia. NEngl JMed.2012;367(9):826-833.

11. Yang G, Zhou Y, Liu X, et al. A mutation in MYD88 (L265P) supports the survival of lymphoplasmacytic cells by activation of Bruton tyrosine kinase in Waldenstrom macroglobulinemia. Blood. 2013;122(7):1222-1232.

12. Treon SP, Cao Y, Xu L, Yang G, Liu X, Hunter ZR. Somatic mutations in MYD88 and CXCR4 are determinants of clinical presentation and overall survival in Waldenstrom macroglobulinemia. Blood. 2014;123(18):2791-2796.

13. Moriuchi M, Moriuchi H, Turner W, Fauci AS. Cloning and analysis of the promoter region of CXCR4, a coreceptor for HIV-1 entry. J Immunol. 1997;159(9):4322-4329.

14. Caruz A, Samsom M, Alonso JM, et al. Genomic organization and promoter characterization of human CXCR4 gene. FEBS Lett. 1998;426(2):271-278.

15. Hunter ZR, Xu L, Yang G, et al. The genomic landscape of Waldenstrom macroglobulinemia is characterized by highly recurring MYD88 and WHIM-like CXCR4 mutations, and small somatic deletions associated with B-cell lymphomagenesis. Blood. 2014;123(11):1637-1646.

16. Xu L, Hunter ZR, Tsakmaklis N, et al. Clonal architecture of CXCR4 WHIM-like mutations in Waldenstrom macroglobulinaemia. $\mathrm{Br} \mathrm{J}$ Haematol. 2016;172(5):735-744.

17. Hunter ZR, Xu L, Yang G, et al. Transcriptome sequencing reveals a profile that corresponds to genomic variants in Waldenstrom macroglobulinemia. Blood. 2016;128(6):827-838.

18. Garcia-Sanz R, Montoto S, Torrequebrada A, et al. Waldenstrom macroglobulinaemia: presenting features and outcome in a series with 217 cases. Br J Haematol. 2001;115(3):575-582.

19. Ghobrial IM. Are you sure this is Waldenstrom macroglobulinemia? Hematology Am Soc Hematol Educ Program. 2012;2012:586-594.

20. Kapoor P, Paludo J, Vallumsetla N, Greipp PR. Waldenstrom macroglobulinemia: what a hematologist needs to know. Blood Rev. 2015;29(5):301-319.

21. Kyle RA, Treon SP, Alexanian R, et al. Prognostic markers and criteria to initiate therapy in Waldenstrom's macroglobulinemia: consensus panel recommendations from the Second International Workshop on Waldenstrom's macroglobulinemia. Semin Oncol. 2003;30(2):116-120. 
22. Gertz MA, Reeder CB, Kyle RA, Ansell SM. Stem cell transplant for Waldenstrom macroglobulinemia: an underutilized technique. Bone Marrow Transplant. 2012;47(9):1147-1153.

23. Louw VJ, Webb MJ. Prognosis and treatment of Waldenstrom's macroglobulinemia. Transfus Apher Sci. 2010;42(2):193-197.

24. Johnson SA, Birchall J, Luckie C, Oscier DG, Owen RG. Guidelines on the management of Waldenstrom macroglobulinaemia. Br J Haematol. 2006;132(6):683-697.

25. Leblond V, Kastritis E, Advani R, et al. Treatment recommendations for Waldenstrom macroglobulinemia from the Eighth International Workshop on WM. Blood. 2016;128(10):1321-1328.

26. Szczepiorkowski ZM, Winters JL, Bandarenko N, et al. Guidelines on the use of therapeutic apheresis in clinical practice - evidence-based approach from the Apheresis Applications Committee of the American Society for apheresis. J Clin Apher. 2010;25(3):83-177.

27. Treon SP, Agus DB, Link B, et al. CD20-directed antibody-mediated immunotherapy induces responses and facilitates hematologic recovery in patients with Waldenstrom's macroglobulinemia. J Immunother (1991). 2001;24(3):272-279.

28. Treon SP, Agus TB, Link B, et al. CD20-directed antibody-mediated immunotherapy induces responses and facilitates hematologic recovery in patients with Waldenstrom's macroglobulinemia. J Immunother. 2001;24(3):272-279.

29. Gertz MA, Rue M, Blood E, Kaminer LS, Vesole DH, Greipp PR. Multicenter phase 2 trial of rituximab for Waldenstrom macroglobulinemia (WM): an Eastern Cooperative Oncology Group Study (E3A98). Leuk Lymphoma. 2004;45(10):2047-2055.

30. Treon SP, Branagan AR, Hunter Z, Santos D, Tournhilac O, Anderson KC. Paradoxical increases in serum IgM and viscosity levels following rituximab in Waldenstrom's macroglobulinemia. Ann Oncol. 2004;15(10):1481-1483.

31. Treon SP, Emmanouilides C, Kimby E, et al. Extended rituximab therapy in Waldenstrom's macroglobulinemia. Ann Oncol. 2005;16(1):132-138.

32. Ghobrial IM, Fonseca R, Greipp PR, et al. Initial immunoglobulin M 'flare' after rituximab therapy in patients diagnosed with Waldenstrom macroglobulinemia: an Eastern Cooperative Oncology Group Study. Cancer. 2004;101(11):2593-2598.

33. Li SC, Chen YC, Evens AM, et al. Rituximab-induced late-onset neutropenia in newly diagnosed B-cell lymphoma correlates with Fc receptor FcgammaRIIIa 158(V/F) polymorphism. Am J Hematol. 2010;85(10):810-812.

34. Wolach O, Bairey O, Lahav M. Late-onset neutropenia after rituximab treatment: case series and comprehensive review of the literature. Medicine (Baltimore). 2010;89(5):308-318.

35. Wolach O, Shpilberg O, Lahav M. Neutropenia after rituximab treatment: new insights on a late complication. Curr Opin Hematol. 2012;19(1):32-38.

36. Weng WK, Negrin RS, Lavori P, Horning SJ. Immunoglobulin G Fc receptor FcgammaRIIIa $158 \mathrm{~V} / \mathrm{F}$ polymorphism correlates with rituximabinduced neutropenia after autologous transplantation in patients with non-Hodgkin's lymphoma. J Clin Oncol. 2010;28(2):279-284.

37. Castillo JJ, Kanan S, Meid K, Manning R, Hunter ZR, Treon SP. Rituximab intolerance in patients with Waldenstrom macroglobulinaemia. Br J Haematol. 2016;174(4):645-648.

38. Furman RR, Eradat H, Switzky JC, et al. A phase II trial of ofatumumab in subjects with Waldenstrom's macroglobulinemia. Blood. 2010;116(21):1795-1795.

39. Treon SP. How I treat Waldenstrom macroglobulinemia. Blood. 2015;126(6):721-732.

40. Dimopoulos MA, Anagnostopoulos A, Kyrtsonis MC, et al. Primary treatment of Waldenstrom macroglobulinemia with dexamethasone, rituximab, and cyclophosphamide. J Clin Oncol. 2007;25(22): 3344-3349.

41. Kastritis E, Gavriatopoulou M, Kyrtsonis MC, et al. Dexamethasone, rituximab, and cyclophosphamide as primary treatment of Waldenstrom macroglobulinemia: final analysis of a phase 2 study. Blood. 2015; 126(11):1392-1394.
42. Rummel MJ, Niederle N, Maschmeyer G, et al. Bendamustine plus rituximab versus CHOP plus rituximab as first-line treatment for patients with indolent and mantle-cell lymphomas: an open-label, multicentre, randomised, phase 3 non-inferiority trial. Lancet. 2013;381(9873):1203-1210.

43. Tedeschi A, Picardi P, Ferrero S, et al. Bendamustine and rituximab combination is safe and effective as salvage regimen in Waldenstrom macroglobulinemia. Leuk Lymphoma. 2015;56(9):2637-2642.

44. Treon SP, Hanzis C, Tripsas C, et al. Bendamustine therapy in patients with relapsed or refractory Waldenstrom's macroglobulinemia. Clin Lymphoma Myeloma Leuk. 2011;11(1):133-135.

45. Castillo JJ, Gustine J, Meid K, Dubeau T, Ghobrial IM, Treon SP. Lower doses of bendamustine are not associated with lower response rates in previously untreated patients with Waldenström macroglobulinemia. Blood. 2016;128(22):2969-2969.

46. Leblond V, Johnson S, Chevret S, et al. Results of a randomized trial of chlorambucil versus fludarabine for patients with untreated Waldenstrom macroglobulinemia, marginal zone lymphoma, or lymphoplasmacytic lymphoma. J Clin Oncol. 2013;31(3):301-307.

47. Dimopoulos MA, Kastritis E, Owen RG, et al. Treatment recommendations for patients with Waldenstrom macroglobulinemia (WM) and related disorders: IWWM-7 consensus. Blood. 2014;124(9): 1404-1411.

48. Treon SP. Proteasome inhibitors in Waldenstrom macroglobulinemia. Blood. 2013;122(19):3243-3244.

49. Kapoor P. Another bidder (BDR) revisits. Blood. 2017;129(4):398-400.

50. Treon SP, Ioakimidis L, Soumerai JD, et al. Primary therapy of Waldenstrom macroglobulinemia with bortezomib, dexamethasone, and rituximab: WMCTG clinical trial 05-180. J Clin Oncol. 2009;27(23): 3830-3835.

51. Ghobrial IM, Xie W, Padmanabhan S, et al. Phase II trial of weekly bortezomib in combination with rituximab in untreated patients with Waldenstrom macroglobulinemia. Am J Hematol. 2010;85(9):670-674.

52. Treon SP, Tripsas CK, Meid K, et al. Carfilzomib, rituximab, and dexamethasone $(\mathrm{CaRD})$ treatment offers a neuropathy-sparing approach for treating Waldenstrom's macroglobulinemia. Blood. 2014; 124(4):503-510.

53. Chauhan D, Tian Z, Zhou B, et al. In vitro and in vivo selective antitumor activity of a novel orally bioavailable proteasome inhibitor MLN9708 against multiple myeloma cells. Clin Cancer Res. 2011;17(16): 5311-5321.

54. Richardson PG, Baz R, Wang M, et al. Phase 1 study of twice-weekly ixazomib, an oral proteasome inhibitor, in relapsed/refractory multiple myeloma patients. Blood. 2014;124(7):1038-1046.

55. Hurchla MA, Garcia-Gomez A, Hornick MC, et al. The epoxyketonebased proteasome inhibitors carfilzomib and orally bioavailable oprozomib have anti-resorptive and bone-anabolic activity in addition to anti-myeloma effects. Leukemia. 2013;27(2):430-440.

56. Dimopoulos MA, Zomas A, Viniou NA, et al. Treatment of Waldenstrom's macroglobulinemia with thalidomide. JClin Oncol.2001;19(16): 3596-3601.

57. Coleman M, Leonard J, Lyons L, Szelenyi H, Niesvizky R. Treatment of Waldenstrom's macroglobulinemia with clarithromycin, low-dose thalidomide, and dexamethasone. Semin Oncol. 2003;30(2):270-274.

58. Treon SP, Soumerai JD, Branagan AR, et al. Thalidomide and rituximab in Waldenstrom macroglobulinemia. Blood. 2008;112(12):4452-4457.

59. Dimopoulos MA, Tsatalas C, Zomas A, et al. Treatment of Waldenstrom's macroglobulinemia with single-agent thalidomide or with the combination of clarithromycin, thalidomide and dexamethasone. Semin Oncol. 2003;30(2):265-269.

60. Treon SP, Soumerai JD, Branagan AR, et al. Lenalidomide and rituximab in Waldenstrom's macroglobulinemia. Clin Cancer Res. 2009;15(1):355-360.

61. Ghobrial IM, Witzig TE, Gertz M, et al. Long-term results of the phase II trial of the oral mTOR inhibitor everolimus (RAD001) in relapsed or refractory Waldenstrom macroglobulinemia. Am J Hematol. 2014;89(3):237-242. 
62. Treon SP, Tripsas CK, Ioakimidis L, et al. Prospective, multicenter study of the MTOR inhibitor everolimus (RAD001) as primary therapy in Waldenstrom's macroglobulinemia. Blood. 2011;118(21):2951-2951.

63. Ghobrial IM, Redd R, Armand P, et al. Phase I/II trial of everolimus in combination with bortezomib and rituximab (RVR) in relapsed/refractory Waldenstrom macroglobulinemia. Leukemia. 2015;29(12):2338-2346.

64. de Rooij MFM, Kuil A, Kraan W, et al. Ibrutinib and idelalisib target B cell receptor- but not CXCL12/CXCR4-controlled integrin-mediated adhesion in Waldenström macroglobulinemia. Haematologica. 2016;101(3):e111-e115.

65. Castillo JJ, Gustine JN, Meid K, et al. Idelalisib in Waldenstrom macroglobulinemia: high incidence of hepatotoxicity. Leuk Lymphoma. 2017;58(4):1002-1004.

66. Treon SP, Tournilhac O, Branagan AR, et al. Clinical responses to sildenafil in Waldenstrom's macroglobulinemia. Clin Lymphoma. 2004; 5(3):205-207.

67. Pals ST, Kersten MJ, Spaargaren M. Targeting cell adhesion and homing as strategy to cure Waldenström's macroglobulinemia. Best Pract Res Clin Haematol. 2016;29(2):161-168.

68. Treon SP, Tripsas CK, Meid K, et al. Ibrutinib in previously treated Waldenstrom's macroglobulinemia. N Engl J Med. 2015;372(15):1430-1440

69. Dimopoulos MA, Trotman J, Tedeschi A, et al. Ibrutinib for patients with rituximab-refractory Waldenström's macroglobulinaemia (iNNOVATE): an open-label substudy of an international, multicentre, phase 3 trial. Lancet Oncol. Epub 2016 Dec 9.

70. Cao Y, Hunter Z, Liu X, et al. The WHIM-like CXCR4S338X somatic mutation activates AKT and ERK, and promotes resistance to ibrutinib and other agents used in the treatment of Waldenstrom's macroglobulinemia. Leukemia. 2015;29(1):169-176.

71. Cao Y, Hunter ZR, Liu X, et al. CXCR4 WHIM-like frameshift and nonsense mutations promote ibrutinib resistance but do not supplant MYD88L265P-directed survival signalling in Waldenström macroglobulinaemia cells. Br J Haematol. 2015;168(5):701-707.

72. Treon SP, Xu L, Hunter Z. MYD88 mutations and response to ibrutinib in Waldenstrom's macroglobulinemia. $N$ Engl J Med. 2015;373(6): 584-586.

73. Byrd JC, Brown JR, O'Brien S, et al. Ibrutinib versus ofatumumab in previously treated chronic lymphoid leukemia. NEngl J Med. 2014;371(3): 213-223.

74. Leong DP, Caron F, Hillis C, et al. The risk of atrial fibrillation with ibrutinib use: a systematic review and meta-analysis. Blood. 2016;128(1): $138-140$.

75. Gustine JN, Meid K, Dubeau TE, Treon SP, Castillo JJ. Atrial fibrillation associated with ibrutinib in Waldenstrom macroglobulinemia. Am J Hematol. 2016;91(6):E312-E313.

76. McMullen JR, Boey EJ, Ooi JY, Seymour JF, Keating MJ, Tam CS. Ibrutinib increases the risk of atrial fibrillation, potentially through inhibition of cardiac PI3K-Akt signaling. Blood. 2014;124(25):3829-3830.

77. Levade M, David E, Garcia C, et al. Ibrutinib treatment affects collagen and von Willebrand factor-dependent platelet functions. Blood. 2014;124(26):3991-3995.
78. Hivert B, Caron C, Petit S, et al. Clinical and prognostic implications of low or high level of von Willebrand factor in patients with Waldenstrom macroglobulinemia. Blood. 2012;120(16):3214-3221.

79. Yang G, Liu X, Chen J, et al. Targeting IRAK1/IRAK4 signaling in Waldenstrom's macroglobulinemia. Blood. 2015;126(23):4004-4004.

80. Yang G, Buhrlage SJ, Tan L, et al. HCK is a survival determinant transactivated by mutated MYD88, and a direct target of ibrutinib. Blood. 2016;127(25):3237-3252.

81. Yang G, Buhrlage S, Tan L, et al. HCK is a highly relevant target of ibrutinib in MYD88 mutated Waldenstrom's macroglobulinemia and diffuse large B-cell lymphoma. Blood. 2015;126(23):705-705.

82. Cao Y, Yang G, Hunter ZR, et al. The BCL2 antagonist ABT-199 triggers apoptosis, and augments ibrutinib and idelalisib mediated cytotoxicity in CXCR4Wild-type and CXCR4WHIM mutated Waldenstrom macroglobulinaemia cells. Br J Haematol. 2015;170(1):134-138.

83. Paulus A, Chitta KS, Akhtar S, et al. Aurora kinase is a therapeutic target in ibrutinib-resistant Waldenstrom macroglobulinemia: in-silico target identification and in-vitro validation. Blood. 2015;126(23): 2754-2754.

84. Kyriakou C, Canals C, Sibon D, et al. High-dose therapy and autologous stem-cell transplantation in Waldenstrom macroglobulinemia: the Lymphoma Working Party of the European Group for Blood and Marrow Transplantation. J Clin Oncol. 2010;28(13):2227-2232.

85. Kyriakou C, Boumendil A, Finel H, et al. Autologous stem cell transplantation (ASCT) for the treatment of patients with Waldenstrom's macroglobulinemia/lymphoplasmacytic lymphoma (WM/LPL). A risk factor analysis by the European Society for Blood and Marrow Transplantation (EBMT) Lymphoma Working Party. Blood. 2014;124(21): 678-678.

86. Kyriakou C, Canals C, Cornelissen JJ, et al. Allogeneic stem-cell transplantation in patients with Waldenstrom macroglobulinemia: report from the Lymphoma Working Party of the European Group for Blood and Marrow Transplantation. J Clin Oncol. 2010;28(33): 4926-4934.

87. Gertz MA, Kyle RA. Hyperviscosity syndrome. J Intensive Care Med. 1995;10(3):128-141.

88. Letendre L, Kyle RA. Monoclonal cryoglobulinemia with high thermal insolubility. Mayo Clin Proc. 1982;57(10):629-633.

89. Michael AB, Lawes M, Kamalarajan M, Huissoon A, Pratt G. Cryoglobulinaemia as an acute presentation of Waldenstrom's macroglobulinaemia. Br J Haematol. 2004;124(5):565.

90. Nobile-Orazio E, Marmiroli P, Baldini L, et al. Peripheral neuropathy in macroglobulinemia: incidence and antigen-specificity of M proteins. Neurology. 1987;37(9):1506-1514.

91. Advani RH, Buggy JJ, Sharman JP, et al. Bruton tyrosine kinase inhibitor ibrutinib (PCI-32765) has significant activity in patients with relapsed/ refractory B-cell malignancies. J Clin Oncol. 2013;31(1):88-94.

92. Furman R, Bilotti E, Graef T. Single-agent ibrutinib demonstrates long-term activity and safety in patients with relapsed/refractory Waldenstrom's macroglobulinemia. Paper presented at: Haematologica, Vienna, Austria; 2015
Cancer Management and Research

\section{Publish your work in this journal}

Cancer Management and Research is an international, peer-reviewed open access journal focusing on cancer research and the optimal use of preventative and integrated treatment interventions to achieve improved outcomes, enhanced survival and quality of life for the cancer patient. The manuscript management system is completely online and includes

\section{Dovepress}

a very quick and fair peer-review system, which is all easy to use. Visit http://www.dovepress.com/testimonials.php to read real quotes from published authors. 